President's Conference

ROYAL

AERONAUTICAL SOCIETY

\title{
RPAS: ACHIEVEMENTS AND CHALLENGES
}

LONDON / 7 - 8 OCTOBER 2015

The 2015 President's

Conference will provide a strategic view of the growth in Remotely Piloted Aircraft System. The conference will provide the opportunity for users, manufacturers and regulators to engage in an unbiased discussion on growing national and international UAS activity, placing the annual RAeS UAS Conference as the premier UAS event.

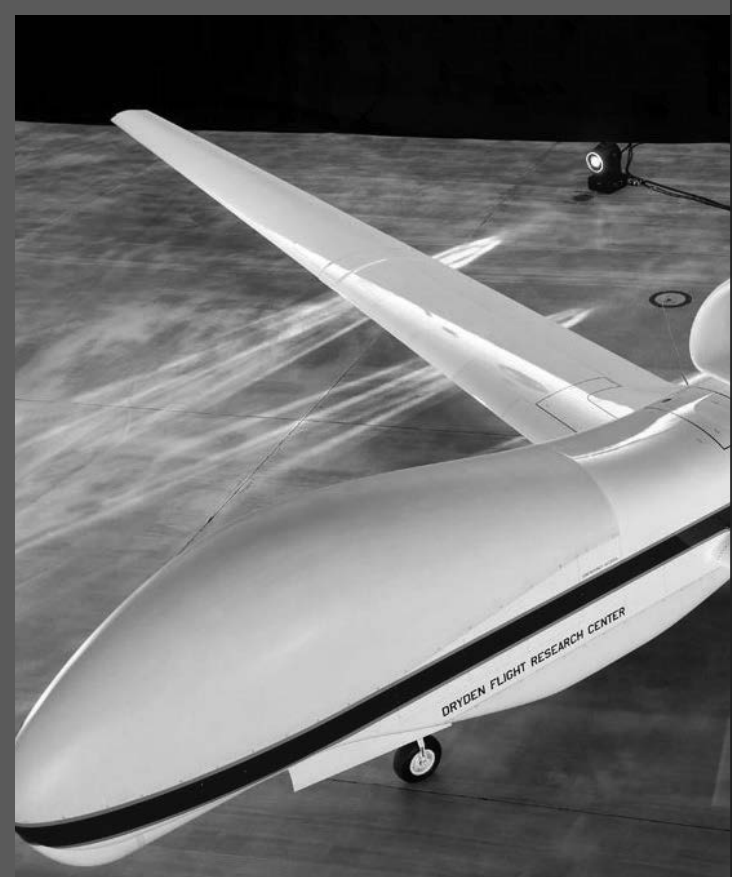

www.aerosociety.com/events

Sponsors

\& GEMERAL ATOMICS
Supporters

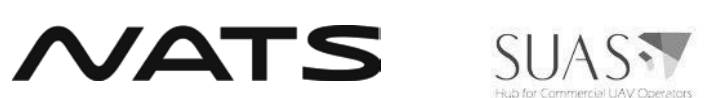




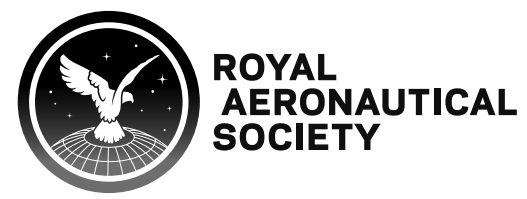

UPCOMING STRUCTURES

\& MATERIALS GROUP CONFERENCES

Publications Partner

THE

AERONAUTICAL JOURNAL

\section{Future Trends in Certification of Advanced Technology Structures 16 September 2015 / Bristol}

This conference will focus on possible changes in the process employed to certify aircraft structures as viewed by both certification authorities and platform/ engine constructors.

\section{Presentations will be given by the general aviation and commercial aircraft field as well as on spacecraft structures and turbine engines. How are manufactures modifying their processes in order to produce new products in a shorter timescale and at lower cost? How are certification authorities changing their requirements to meet the new technologies and reduced timescales?}

\section{5th Aircraft Structural Design Conference 4- 6 October 2016 / Lisbon, Portugal}

The 5 th conference to be held in this series will take place at the Institut Superior Tecnico in Lisbon, Portugal in 2016. This event aims to provide a platform for teh presentation of new ideas computerised design methods and algorithms for the design and development of civil and military aircraft both manned and unmanned, over the course of the next decade. A call for papers will be opening shortly

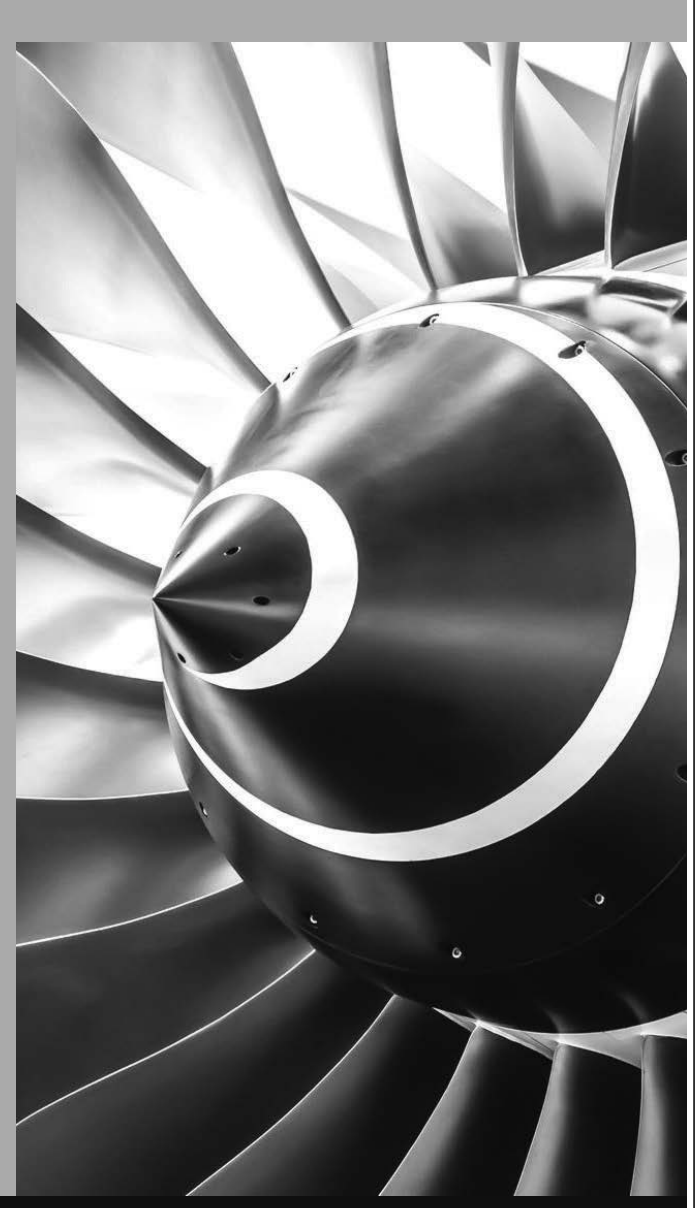

\section{www.aerosociety.com/events}

Please visit our website to find out more information on both events, www.aerosociety.com/events.

Sponsorship and exhibition opportunities are available at both events. To find out more please contact the Conference and Event Department on +44 (0)20 76704345 or conference@aerosociety.com 


\section{THE AERONAUTICAL JOURNAL Instructions for Authors}

\section{CORRESPONDING AUTHOR}

The author willing to handle correspondence at all stages of refereeing, production and post-production stages should be indicated clearly on the covering letter. Their full name, full postal address and telephone number should be included with their email address.

\section{PREPARATION OF PAPERS}

\section{General}

Initial submissions must comprise a PDF, Word or LaTeX file including figures. These must be sent to the Editor Via The Aeronautical Journal's dedicated Manuscript Management System (MMS) at www.edmgr.com/aeroj An accompanying letter, also to be submitted via the MMS site must include a clear request for publication and state that the paper has not been published previously or submitted for publication elsewhere. The author will then be invited to suggest three appropriate referees and a suitable Associate Editor (from the list printed on the inside front cover of all Aeronautical Journals) to handle the submitted manuscript. Keywords describing the main subject area(s) covered by the paper should also be given. There will also be an opportunity on the MMS to state whether your paper is to be considered under the Open Access scheme.

The receipt of papers will be acknowledged by email with a reference number which should be used in all correspondence.

Prior to submission, if the paper originates from non-English speaking author(s), manuscripts should be read critically by a third party who has a good grasp of the English language and is familiar with the subject area. Authors must also obtain permission where necessary to use any material in a paper which is copyright or the property of any other persons or entity, including their employers. Any fees incurred are the sole responsibility of the author(s). The paper will also be published on the Internet. The Aeronautical Journal is marketed and sold internationally.

There exists the option of having papers published in colour in the paper version. This can be carried out for a fee agreed and invoiced before publication. All papers appear in colour on the RAeS website.

Figures

All figures must be provided by the author(s) and must be included with the initial manuscript. All figures should be numbered and given captions. References to figures in the text should be referred to as; Fig. 1, Figs 2 and 3 or Figure 1 if at the start of a sentence. Photographs should be provided electronically via the MMS site at a minimum of 250dpi. Graphs, tables, charts etc. should be at least 150dpi. Figures and photos are accepted in the following formats: JPEG, TIFF, PDF and EPS.

\section{STYLE GUIDELINES}

Papers must be in English and should comply with the structural guidelines below and should preferably not exceed 10,000 words. The following is the recommended generic format:

Title: The title should be kept short and concise.

Authors' names and affiliations: Names should be presented in the order they should appear on the published paper. Each author's organisation to which they are associated should be included with accompanying address, please note the authors' email addresses will be published unless requested not to.

Abstract: An abstract of around 150 words which summarises the paper and contains no references.

Nomenclature: A list of all symbols and abbreviations used in the text and figures, whether familiar or not, should be given in alphabetical order with, for example, c before $\mathrm{C}$ and all English letters listed before Greek symbols. Subscripts and superscripts should be listed separately where possible. SI units are preferable.

Introduction: Discuss the raison d'être of the work, including previous work by others and how the work presented aims to advance or complement this.

Equations: Equations must be numbered in brackets (...1). Each equation should be produced electronically in WORD preferably using either Equation Manager or Mathtype. Variables should be in italics. Constants should be in plain text. Vectors and matrices should be in plain text but bold. Cos, Sin, Tan should begin in capitals and be in plain text.
Conclusions: This section should be very concise and bullet points are recommended for clarity. The degree to which the aims have been achieved should be portrayed clearly to the reader. Suggestions for future work or comments on work in progress are encouraged.

References: References should be numbered sequentially in the text as they occur and placed at the end of the manuscript. For example, most commonly for papers(1.) and reports(2.). Author's names should be in small Caps. They should be presented as follows:

1. MLLLER, $P$ and WILSON, M. Wall jets created by single and twin high pressure jet impingement, Aeronaut J, March 1993, 97, (963), pp 87-100.

2. Green, J.E., WeEks, D.J. and Brooman, J.W.F. Prediction of turbulent boundary layers and wakes in compressible flow, ARC R\&M № 3791, 1979.

and for books(3.)

3. King-Hele, D. Satellite Orbits in an Atmosphere, Blackie, Glasgow, 1987.

Appendices: If no suitable reference is available appendices may be used to clarify certain points, such as a step in the theoretical analysis.

Tables: Tables should have a number and a caption. Each table should be cited in numerical order in the text.

\section{TECHNICAL NOTES}

These can be up to 2,000 words in length and have no set form. They can be abstracts, comments upon unpublished papers, notes on interim results or a call for further research. They do not have to contain figures or nomenclature and may be in the form of a letter. Manuscripts submitted in this category tend to be reviewed and published more quickly than a full paper.

\section{THE REFEREEING PROCESS}

A minimum of two referees are used for a paper and it is requested that authors suggest the names and addresses of three possible independent referees to review their paper although we reserve the right not to use them. The manuscript is sent by an Associate Editor to two referees with a request for a thorough review. Associate Editor to two referees with a request for a thorough review.

Once both referees have replied, their comments are sent to the authors and if changes are recommended they are invited to revise the paper as suggested. It is helpful if a list of those changes, and direct replies to them are included by the author with the revised version.

Unless a paper has been accepted 'as is' by both referees, a revised manuscript will be sent once more to the referees. If the Associate Editor feels, having considered the second reviews, that the authors have not responded adequately to the original reviews of the referees, then the paper will be rejected. Thus it is imperative that all comments are addressed properly by authors. A third referee may be approached if the Associate Editor thinks this is appropriate. The Editor ultimately reserves the right to reject a paper on grounds of quality or lack of co-operation from authors. The above process is carried out via the MMS system.

\section{Acceptance}

Once a paper is accepted, the authors will be invited to send the approved version of the text by the MMS system or email. The preferred text format is Microsoft WORD with separate individual electronic image files (JPEG, EPS, PDF or TIFF files at 250dpi minimum) for any figures used. Latex files are also accepted. The positions of each equation and figure should be indicated in the text.

\section{Following acceptance}

Approximately one month before publication, authors are sent page proofs for checking and should keep this in mind if likely to be away during this time. Authors should expect just a single set of proofs to be sent to them for checking. The Editor of The Aeronautical Journal reserves the right to publish a paper after just one set of corrections.

\section{CONDITIONS OF PUBLICATION}

Unless specifically attributed, no material in The Aeronautical Journal should be taken to represent the opinion of the RAeS and its Council. Copyright lies with the publisher on publication. 
ROYAL

AERONAUTICAL

SOClitY 